\title{
Long term psychological outcome for women with congenital adrenal hyperplasia: cross sectional survey
}

\author{
John F Morgan, Helen Murphy, J Hubert Lacey, Gerard Conway
}

Department of Mental Health, St George's Hospital Medical School, University of London, London SW17 0RE

John F Morgan senior lecturer Helen Murphy clinical lecturer J Hubert Lacey professor

Department of Endocrinology, The Middlesex Hospital, London W1T 3AA Gerard Conway senior lecturer Correspondence to: J F Morgan jmorgan@sghms.ac.uk

BMJ 2005;330:340-1
Management of conditions associated with intersex, such as congenital adrenal hyperplasia, is controversial. A recent editorial in the $B M J$ called for long term studies of outcome. ${ }^{1}$ Females (genotype XX) with congenital adrenal hyperplasia are born with ambiguous genitalia, have feminising genitoplasty soon after birth, and often have repeated genital surgery and genital examinations in adolescence. This has raised fears that the condition and its management adversely affect psychosexual development or psychosocial adjustment. ${ }^{2}$ The "serious deficiency of any evidence base" on long term outcome prompted us to investigate the hypothesis that psychiatric morbidity is increased and that social and psychological adjustment is impaired in women with congenital adrenal hyperplasia.

\section{Participants, methods, and results}

We did a cross sectional study of a clinic based sample of women with congenital adrenal hyperplasia. All were genetically female, some had feminising genitoplasty soon after birth, and all were raised as female. We recruited 18 sequential female patients (aged 18-36) with congenital adrenal hyperplasia from an endocrinology clinic at the Middlesex Hospital, London, in 1997-8. We assessed participants with validated structured interviews (the Eating Disorder Examination, 12th edition, and the Structured Clinical Interview for DMSIV-R (Diagnostic and Statistical Manual of Mental Disorders, fourth edition, revised)) and questionnaires (the General Health Questionnaire 30, the modified Social Adjustment Scale, ${ }^{3}$ and Rosenberg's Self Esteem Inventory). All patients approached agreed to participate (table). ${ }^{4}$

Two participants met diagnostic criteria for past mood disorder, five for past anxiety disorder, and one for past alcohol misuse. General health questionnaire scores were consistent with these findings, with a sensitivity of $100 \%$ and specificity of $88 \%$ for detection of depression. Social adjustment scores fell within the normal range for all role areas examined (table), and self esteem scores (mean 4.83, standard deviation 4.57) were above average (possible range -15 to +15 ).

No women met DSM-IV criteria for an eating disorder. Reflecting eating behaviours and attitudes, Eating Disorder Examination scores were comparable to normative data on subscales of restraint $(0.70,0.87 v$ $0.79,0.97)$, shape concern $(1.17,0.96 v 1.14,0.98)$, and weight concern $(1.02,1.28 v 1.00,0.87)$, but eating concern was raised $(0.72,0.60 v 0.20,0.51)$.

Only four participants rated themselves as sexually active, of whom two rated nil sexual enjoyment. Two participants categorised themselves as homosexual and two as bisexual, and sexual orientation was not associated with differences in any measure of psychosocial adjustment.

\section{Comment}

Women with congenital adrenal hyperplasia are psychologically well adjusted and do not show substantially increased psychiatric disorder or deficits of social adjustment compared with population data. Low levels of sexual activity and higher levels of non-heterosexual orientation are indicated, although legitimate normative data is lacking. Levels of disordered eating are not significantly different from population norms, despite increased exposure to sociocultural risk factors for eating disorders, though this may reflect a type II error.

Limitations of the study include the small sample size and the lack of a control group, which would have the same stresses as the congenital adrenal hyperplasia group but lack the stigmata of the illness. As such a control group does not exist, a descriptive comparison was made with the general population.

Although a previous study of childhood psychiatric morbidity in intersex people found increased preva-

This article was posted on bmj.com on 26 January 2005: http://bmj.com/ cgi/doi/10.1136/bmj.38334.427361.D3

Psychiatric morbidity as defined in DSM-IV and psychosocial function in 18 women with congenital adrenal hyperplasia compared with normative data

\begin{tabular}{|c|c|c|c|c|c|}
\hline \multicolumn{3}{|c|}{ DSM-IV psychiatric diagnosis } & \multicolumn{3}{|c|}{ Social adjustment score ${ }^{3}$} \\
\hline & $\begin{array}{l}\text { Congenital adrenal } \\
\text { hyperplasia (No) }\end{array}$ & $\begin{array}{c}\text { Normative data from } \\
\text { epidemiological } \\
\text { catchment area study } \\
(\%)\end{array}$ & & $\begin{array}{l}\text { Congenital adrenal } \\
\text { hyperplasia (mean } \\
\text { (standard deviation)) }\end{array}$ & $\begin{array}{l}\text { Normative data from } \\
\text { epidemiological } \\
\text { catchment area study } \\
\text { (mean) }\end{array}$ \\
\hline $\begin{array}{l}\text { Major depressive } \\
\text { disorder }\end{array}$ & 2 & 18 & Work outside home & $1.62(0.23)$ & NA \\
\hline Social phobia & 2 & 1.7 & Housework & $1.74(0.51)$ & 1.60 \\
\hline Panic disorder & 1 & 0.8 & Social and leisure & $1.68(0.44)$ & 1.80 \\
\hline $\begin{array}{l}\text { Generalised anxiety } \\
\text { disorder }\end{array}$ & 2 & NA & Parental & $1.43(0.18)$ & 1.55 \\
\hline \multirow[t]{4}{*}{ Current alcohol misuse } & 1 & 5 & Extended family & $1.76(0.49)$ & 1.65 \\
\hline & & & Relationship & $1.87(0.30)$ & 1.85 \\
\hline & & & Family unit & $1.88(0.27)$ & 1.88 \\
\hline & & & Total score & $1.70(0.26)$ & 1.70 \\
\hline
\end{tabular}

DSM-IV=Diagnostic and Statistical Manual of Mental Disorders, fourth edition 
lence of mental disorder, ${ }^{5}$ and accepting that some individuals with congenital adrenal hyperplasia may struggle to adapt, we conclude that the women with congenital adrenal hyperplasia in our small study are psychologically robust. Future studies must consider factors contributing to good psychological outcome, including timing of surgery and communication with parents and patients.

Contributors: JFM, JHL, and GC originated and designed the study. JFM collected the data. JFM and HM analysed and interpreted the data and drafted the manuscript. GC, JHL, and JFM critically revised the manuscript. JHL supervised the study. JFM is guarantor.

Funding: No additional funding.

Competing interests: None declared.

Ethical approval: Research ethics committee for the Central Middlesex Hospital.

Creighton S, Minto C. Managing intersex. BMJ 2001;323:1264-5.

2 Meyer-Bahlburg HFL. Gender and sexuality in classic congenital adrenal hyperplasia. Endocrinol Metab Clin North Am 2001;30:155-71,VIII

\section{What is already known on this topic}

Intersex children may have increased prevalence of psychiatric morbidity; research on adult psychological outcomes is limited despite fears that the condition may adversely affect psychosocial adjustment

\section{What this study adds}

Most women with congenital adrenal hyperplasia have good long term psychological outcome, with no dramatic increase in psychological morbidity, good social adjustment, and no deficit in self esteem

3 Cooper P, Osborn M, Gath D, Feggetter G. Evaluation of a modified selfreport measure of social adjustment. BJPsych 1992:141:68-75.

Kessler RC, McGonagle KA, Zhao S, Nelson CB, Hughes M, Eshleman S, et al. Lifetime and 12-month prevalence of DSM-III-R psychiatric disorders in the United States: results from the national comorbidity survey. Arch Gen Psychiatry 1994;51:8-19.

5 Slijper FME, Drop SL, Molenaar JC, de Muinck Keizer-Schrama MD. Long term psychological evaluation of intersex children. Arch Sex Behav 1998;27:125-45.

(Accepted 1 December 2004)

doi 10.1136/bmj.38334.427361.D3

\title{
Commentary: A support group's perspective
}

\author{
Melissa L Cull
}

Living with congenital adrenal hyperplasia (CAH) poses many challenges, especially for women-the issues of genital surgery, disclosure, informed consent, weight, and general wellbeing not to mention having a chronic condition that is life threatening. Not only does working as a research assistant provide insight into how the medical profession views these conditions, but also working voluntarily with support groups for $\mathrm{CAH}$ for many years and also having CAH myself gives me insight that few doctors or psychologists will ever see or experience.

More research is now being done into the psychological long term outcomes of women with $\mathrm{CAH}$, and that is good to see. ${ }^{1}$ Although I am glad that the small cohort of women in the paper generally had good outcomes, support groups tend to hear a somewhat different story. ${ }^{2}$ Perhaps only people who are dissatisfied with their treatment come to support groups-though going by the rarity of the condition and the comparative number of members it shows many are not surprisingly dissatisfied-but we get people who are satisfied as well. Long term qualitative and quantitative research is important, but the difficulty is getting a large number of participants.

Depression and stress are often reported, particularly to do with relationships, with sexual difficulties after surgery and weight problems associated with steroid replacement. Non-disclosure, shame, secrecy, and stigmas attached to having ambiguous genitalia, an intersex condition, and surgery to "normalise" all place a heavy toll on a woman's psychological wellbeing. What is normal, anyway, if everyone is individual and different?

As more long term surgical outcome studies are done, ${ }^{3}$ it can be seen that the result is psychological as well as physical impact. Genital surgery as young children that was not personally consented to often causes compromised genital sensation and inability to orgasm, and functional damage can give rise to feelings of loss of body ownership. Surgery is often cited as "one stage fix all," but many women need repeat procedures and ongoing dilatation treatment, which can be a constant reminder of difference.

Many women with CAH avoid social situations, frightened that people will find out they have a rare misunderstood condition. Fear of rejection conditioned by parents and the medical profession forces them to avoid intimate contact let alone enter into sexual relationships. Body image for women is important, ${ }^{4}$ and it is dependent on how well the family adjust to having a daughter with CAH as well as how many genital examinations and how they are done. In turn, body image and self esteem affect avoidance of social situations.

A recent paper questions whether it is better to bring up children with such conditions without surgical intervention until they are old enough to be informed and consent themselves but also stipulates multidisciplinary care to reduce any psychological problems. ${ }^{5}$

Although most women with CAH do cope well, others find it difficult. Much stigma is still attached to seeking psychological help and particularly so with intersex conditions. Multidisciplinary one stop patient centred care with endocrinology, gynaecology, and psychology expert teams are now gradually becoming the excellent cornerstone of care for CAH. Women who attend these clinics such as the authors' are coping much better psychologically. Were the study to be repeated in conventional clinics, I am sure the results would unfortunately be less positive.

Competing interests: None declared.

1 Morgan JF, Murphy H, Lacey JH, Conway GS. Long-term psychological outcomes of women with congenital adrenal hyperplasia: cross-sectional survey. BMJ 2005; doi 10.1136/bmj.38334.427361.D3.

2 Cull M. Treatment of intersex needs open discussion. BMJ 2002:324:919. 3 Creighton SM, Minto CL. Managing intersex. BMJ 2001;323:1264-5.

4 May B, Boyle M, Grant D. A comparative study of sexual experiences: women with diabetes and women with congenital adrenal hyperplasia. $J$ Health Psychol 1996;1:479-92.

5 Ahmed SF, Morrison S, Hughes IA. Intersex and gender assignment: the third way? Arch Dis Child 2004;89:847-50.

doi $10.1136 /$ bmj.38365.883843.79
17 Newton Road, Lichfield, Staffordshire, WS13 7EF Melissa L Cull founder of the adrenal hyperplasia network (www.ahn.org.uk)

Melissa.cull@ mlcull.demon.co.uk 